\title{
Investigation of Inhibition Effect and Determination of Some Quantum Chemical Parameters of an Organic Compound on the Carbon Steel in Sulfuric Acid Medium
}

\author{
M.J.Bahrami ia, c, M. Yazdizadeh ${ }^{\text {a }}$, M. Shahidi ${ }^{\text {b }}$, S.M.A. Hosseini ${ }^{\text {a }}$ \\ ${ }^{a}$ Department of Chemistry, Shahid Bahonar University of Kerman, Kerman 76175, Iran. \\ E-mail:m.j.b.1386@gmail.com \\ ${ }^{b}$ Department of Chemistry, Kerman Branch, Islamic Azad University, Kerman, Iran. \\ ${ }^{c}$ Young Researchers Society, Shahid Bahonar University of Kerman, Kerman 76175, Iran
}

\section{ABSTRACT}

The inhibition ability of [3-(4-methyl-pyridin-2-y1)-4-oxo-2-phenylimino-thiazolidin-5-ylidene]-acetic acid ethyl ester (MOTAE) on the corrosion behavior of carbon steel in $0.5 \mathrm{M}$ sulfuric acid solution was investigated using weight loss and potentiodynamic polarization techniques. The inhibition efficiencies increased as the concentration of the compound was increased. The calculated inhibition efficiencies from the investigated methods were in good agreement. Potentiodynamic polarization measurements indicate that MOTAE acts as a mixed type inhibitor. The adsorption of inhibitor on the steel surface obeys Langmuir adsorption isotherm. Fourier transform infrared spectroscopy (FTIR) and scanning electron microscopy (SEM) were used to characterize the surface of the alloy. The structure of inhibitor was optimized using three quantum chemical levels. Some quantum chemical parameters as well as Mulliken charge densities for this molecule were computed and discussed.

Keywords: Corrosion inhibitor; Quantum chemical parameters; Carbon Steel; Adsorption isotherm; Fourier transform infrared spectroscopy.

\section{Council for Innovative Research}

Peer Review Research Publishing System

\section{Journal: Journal of Advances in Chemistry}

Vol. 11, No. 8

editorjaconline@gmail.com, www.cirjac.com 


\section{INTRODUCTION}

The corrosion of materials is one of the main problems facing industrial processes, generating huge financial losses. Metallic industrial structures are often exposed to conditions that facilitate corrosive processes. For example, acidic solutions, which are widely used in acid pickling, industrial acid cleaning and oil refinery equipment cleaning, promote the acceleration of metallic corrosion, affecting the performance and durability of the treated equipment [1].

The application of acid corrosion inhibitors in industry is widely growing to prevent or minimize the material loss during the contact with acid [2]. The most common acids that are used for investigation of the corrosion behavior of steel alloys in acidic media are $\mathrm{HCl}$ and $\mathrm{H}_{2} \mathrm{SO}_{4}$. Organic compounds, containing nitrogen, sulfur, aromatic rings and oxygen atoms, are usually the most favorable acid inhibitors [3-12]. Literature reviews show that these substances are effective inhibitors due to their adsorption on the metal surface. It is proved that compounds containing oxygen groups are capable of forming more strong and stable Fe(III) complexes while those containing nitrogen groups are capable of forming more stable Fe(II) complexes [13].

Recently, quantum chemical calculations are used to study the reaction mechanism and to interpret the experimental results [14]. The inhibition effect mainly depends on some physicochemical and electronic properties of the organic inhibitor which relate to its functional groups, steric effects, electronic density of donor atoms and orbital character of donating electrons and so on. For instance, highest occupied molecular orbital energy $\left(\mathrm{E}_{\text {HOMO }}\right)$, lowest unoccupied molecular orbital energy ( $E_{\text {LUMO }}$ ), atomic charges and dipole moment are quite popular quantum chemical parameters for the study of the corrosion phenomenon [15].

In this research, [3-(4-methyl-pyridin-2-y1)-4-oxo-2-phenylimino-thiazolidin-5-ylidene]-acetic acid ethyl ester, there after called MOTAE (Fig. 1), was used as the inhibitor in sulfuric acid solution. Quantum chemical calculations were employed to know the possible active centre(s) responsible for the adsorption of MOTAE. In order to determine the adsorption mechanism, some quantum chemical parameters ( $\mathrm{E}_{\text {Hомо, }} \mathrm{E}_{\text {LUMO, }} \mathrm{E}_{\text {LUMO-}} \mathrm{E}_{\text {Hомо, }} \eta$ : absolute hardness; $\mathrm{S}$ : softness and $\mu$ : the dipole moment as well as Mulliken charge of each atom) were calculated at three quantum chemical levels. The frontier molecular orbitals, namely, the highest occupied molecular orbital (HOMO) and lowest unoccupied molecular orbital (LUMO) were evaluated.

\section{EXPERIMENTAL}

Fresh solutions of the $0.5 \mathrm{M} \mathrm{H}_{2} \mathrm{SO}_{4}$ were prepared for each experiment using analytical grade of sulfuric acid (98\%) and distilled water. The best concentration range of inhibitor was $2.5-15 \mathrm{ppm}$. Steel sheets of $1 \mathrm{~cm} \times 1 \mathrm{~cm} \times 1 \mathrm{~cm}$ were used for the determination of weight loss measurements. Before each experiment the samples were abraded using emery papers (grades 400-3000), washed with distilled water, degreased with ethanol and finally dried at room temperature. The initial weight of each specimen was recorded, before immersion in the test solution, using an analytical balance (precision: $\pm 0.1 \mathrm{mg}$ ). Then, the specimens were immersed in $100 \mathrm{ml}$ of $0.5 \mathrm{M}$ sulfuric acid solution without and with different concentrations of inhibitor. Potentiodynamic polarization measurements were carried out in a tree-electrode cell using BHP 2063+ELECTROCHEMICAL ANALYSIS SYSTEM instrument. A saturated calomel electrode was used as a reference electrode and a Pt electrode as a counter. Working electrodes were prepared in such a way that the exposed area was $1 \mathrm{~cm}^{2}$. Before each polarization the open circuit potential was stabled within $30 \mathrm{~min}$. The cell was equipped so that the temperature during each experiment was kept constant and measurable. FTIR spectra were recorded in a BrukerTensor27- FTIR spectrophotometer, which extended from 4000 to $700 \mathrm{~cm}^{-1}$, using $\mathrm{KBr}$ disk technique. First the pure MOTAE was mixed with $\mathrm{KBr}$ and disk made. The steel specimens were prepared as described above, and were immersed in $0.5 \mathrm{M} \mathrm{H}_{2} \mathrm{SO}_{4}$ containing the optimum concentration of inhibitor. After 24 hours of immersion the specimens were cleaned with distilled water and dried at room temperature. Then the thin adsorbed film formed on steel surface was rubbed with a small amount of $\mathrm{KBr}$ powder and a $\mathrm{KBr}$ disk was prepared using this powder. The morphology of alloy surface after polarization test in acidic solutions containing optimum concentration of inhibitor was examined by a scanning electron microscope (model: CamScan MV2300, Czech \& England). For theoretical study complete geometry of molecule optimized with Gaussian 2009 program [16], at three quantum chemical levels, i.e. DFT (B3LYP/6-31G (d, p)), HF $(6-31 G(d, p))$ and semi-empirical $(A M 1)$. The quantum chemical parameters for each level obtained from the corresponding optimized structure.

\section{RESULTS AND DISCUSSION}

\section{Weight loss measurements}

After 24 hours of immersion in the test solution, the specimens were cleaned, dried and reweighted. The corrosion rate of carbon steel was determined using eq.1.

$W=\frac{\Delta m}{s t}$

Where $\Delta \mathrm{m}$ is mass loss, $\mathrm{s}$ is the area of specimen and $\mathrm{t}$ is immersion time [17].

The inhibition efficiencies were calculated using eq.2.

$$
I E \%=\left(\frac{W_{\text {corr }}-W_{\text {inh }}}{W_{\text {corr }}}\right) \times 100
$$


Where, $\mathrm{W}_{\text {corr }}$ and $\mathrm{W}_{\text {inh }}$ are corrosion rates of carbon steel without and with different concentrations of inhibitor, respectively. The results of weight loss measurements are listed in Table 1. As it is seen, increasing the concentration of the inhibitor increases the inhibition efficiencies. At an optimum concentration of inhibitor the inhibition efficiency reaches a maximum of $93 \%$. Therefore the inhibitor could be of commercial importance since it is effective at low concentration i.e. in the 15 ppm range. Enhancement of inhibition efficiencies shows that during the adsorption of inhibitor, a protective layer is formed on the surface of alloy.

\section{Polarization measurements}

In order to gain a better knowledge concerning classification of a compound as an anodic, cathodic ormixed type inhibitor and its effect on the kinetics of the anodic and cathodic reactions, etc.,polarization measurements have been carried out. The polarization curves reveal that both anodic and cathodic reactions are affected by increasing inhibitor concentration (Fig. 2). The inhibition efficiency for each concentration of MOTAE was calculated using eq. 3.

$$
I E \%=\left(\frac{i_{\text {corr }}-i_{\text {inh }}}{i_{\text {corr }}}\right) \times 100
$$

Where, $\mathrm{i}_{\text {corr }}$ and $\mathrm{i}_{\text {inh }} i_{\text {corr }}$ are corrosion current densities without and with different concentrations of inhibitor. The electrochemical parameters such as corrosion current density $\left(\mathrm{i}_{\text {corr }}\right)$, corrosion potential $\left(\mathrm{E}_{\text {corr }}\right)$, cathodic and anodic Tafel slopes $\left(\beta_{\mathrm{c}}, \beta_{\mathrm{a}}\right)$ and inhibition efficiencies (IE \%) are given in Table 1. It is observed that in the presence of inhibitors both anodic and cathodic Tafel slopes almost remain unchanged, indicating that the inhibitors acted by merely blocking the reaction sites of the metal surface without changing the anodic and cathodic reaction mechanisms [12]. The inhibition efficiency increases with increasing the concentration of inhibitor. Increasing concentration of the inhibitor decreases corrosion current densities but do not affect the corrosion potentials noticeably. if the displacement in corrosion potential in presence of inhibitor is $>85 \mathrm{mV}$ with respect to corrosion potential in absence of inhibitor, the inhibitor can be seen as a cathodic or anodic type; and if the displacement is $<85$, the inhibitor can be seen as mixed type [18, 19]. Therefore, according to table 1 , MOTAE is considered as a mixed type inhibitor. Increasing the inhibition efficiencies with addition of inhibitor into the solutions confirms the formation of a thin protective film on the surface.

\section{Effect of temperature}

Analysis of the temperature dependence of inhibition efficiency as well as comparison of corrosion activation energies in absence and presence of inhibitor gives some insight into the possible mechanism of inhibitor adsorption [20]. In order to evaluate the adsorption of inhibitor and to calculate thermodynamic and activation parameters of the corrosion processes of carbon steel in acidic media, the effect of temperature on the polarization curves and corrosion parameters $\left(E_{c o r r}, i_{c o r r}\right.$ and $(\mathrm{E})$ in the absence and presence of optimum concentration of inhibitor was studied. The polarization curves are illustrated in Fig. 3 and the corrosion parameter values at different temperatures are listed in Table. 2. The results obtained from Polarization curves show an increase in current density and decrease in IE\% with increasing temperature. Corrosion potential almost remains unchanged with increasing temperature. The dependence of corrosion rate on temperature can be expressed by the Arrhenius equation [21, 22]:

$$
\mathrm{i}_{\text {corr }}=\mathrm{A} \exp \left(\frac{-\mathrm{E}_{\mathrm{a}}}{\mathrm{RT}}\right)
$$

Where, $i_{\text {corr }}$ is corrosion current density, $A$ is the frequency factor, $E_{a}$ is the activation energy of the metal dissolution reaction, $R$ is the gas constant and $T$ is the absolute temperature. The $E_{a}$ values in the presence and absence of inhibitor can be determined from the slopes of Arrhenius plots (log $\mathrm{i}_{\text {corr }}$ versus 1/T (Fig. 4)). Calculated activation energies for the corrosion process in the absence and presence of inhibitor are given in Table. 3. A decrease in inhibition efficiency with rise in temperature with analogous increase in corrosion activation energy in the presence of inhibitor compared to its absence is frequently interpreted as being suggestive of formation of an adsorption film of physical (electrostatic) nature $[20,23]$.

\section{Adsorption isotherm}

Adsorption isotherms can provide fundamental information dealing with the interactions between the inhibitor molecule and the metal surface [24, 25]. Physiorption is due to electrostatic attractive forces between the inhibiting organic ions or dipoles and the electrically charged surface of the metal. Chemisorption is due to interaction between unshared electron pairs or $\pi$-electrons of the adsorbate with the metal in order to form a coordinate type of bond. Molecules containing lone pair electrons, aromatic rings or hetero atoms such as $\mathrm{N}, \mathrm{P}, \mathrm{Se}, \mathrm{O}$ and $\mathrm{S}$ are capable of forming these coordinate types of bonds [26-28]. The inhibition process seems to be the result of adsorption so that the surface coverage can be related directly to the inhibition efficiency as below:

$$
K C=\frac{\theta}{1-\theta}
$$

Where $\theta$ is the surface coverage and IE\% is the inhibition efficiency. The surface coverage values were tested graphically to fit a suitable adsorption isotherm. The plots of $\mathrm{C} / \Theta$ vs. $\mathrm{C}$ yielded a straight line indicating that the adsorption of inhibitor on the metal surface obeys Langmuir adsorption isotherm (Fig. 5). The Langmuir equation can be expressed by eq.5:

$$
\theta=\frac{I E \%}{100}
$$

Where $\mathrm{C}$ is the inhibitor concentration and $\mathrm{K}$ is the adsorption equilibrium constant. 


\section{Thermodynamic parameters}

The relation of constant $\mathrm{K}$ with the standard free energy can be determined by eq.6.

$$
K=\frac{1}{55.5} \exp \left[\frac{-\Delta G}{(R T)}\right]
$$

Where, 55.5 is the molar concentration of water [29]. The negative values of $\Delta \mathrm{G}$ indicate that the adsorption of the inhibitor on the metal surface is spontaneous. Generally values of $\Delta G$ up to $-20 \mathrm{~kJ} / \mathrm{mol}$ involve physical adsorption while those more negative than $-40 \mathrm{~kJ} / \mathrm{mol}$ include chemical adsorption [30, 31].

Van't Hoff equation is expressed as below:

$$
\ln K=\frac{-\Delta H}{R T}+\text { cons } \tan t
$$

Adsorption enthalpy, $\Delta \mathrm{H}$, were calculated using the plot of In $\mathrm{K}$ versus $1 / \mathrm{T}$ (Fig.6).

adsorption entropy $\left(\Delta S_{\text {ads }}\right)$ is calculated from the eq.7:

$$
\Delta G=\Delta H-T \Delta S
$$

Thermodynamic parameters are listed in Table 3. The obtained value of $\Delta \mathrm{G}$ indicate that a combination of physical and chemical adsorption can take place on the alloy surface in $0.5 \mathrm{M} \mathrm{H}_{2} \mathrm{SO}_{4}$ solution. However, chemisorption mechanism precedes physical adsorption. The negative values of $\Delta \mathrm{H}$ show the exothermic adsorption of inhibitor, while, The positive value of calculated adsorption entropy means that the adsorption process is accompanied by an increase in entropy, which is the driving force for the adsorption of inhibitor onto the alloy surface [12]

\section{Forier transform infrared spectroscopy (FTIR)}

Fourier transform infrared spectroscopy is a well-established characterization tool offering a 'fingerprint' for chemical compounds [32]. Several researchers [33, 34] have confirmed that FTIR spectrometer is a powerful instrument that can be used to determine the type of bonding for organic inhibitors absorbed on the metal surface. In this paper, FTIR spectrometer was used to identify whether there was adsorption and to provide new bonding information on the steel surface after immersion in the inhibited $\mathrm{H}_{2} \mathrm{SO}_{4}$ solution [35]. The FTIR spectrum of pure MOTAE is shown in Fig. 7. a. The sharp peak at $1699 \mathrm{~cm}^{-1}$ is attributed to $\mathrm{C}=\mathrm{O}$ stretching vibrations in ester group while the peak at $1586 \mathrm{~cm}^{-1}$ is assigned to $\mathrm{C}=\mathrm{O}$ stretching vibrations in amide group. The $\mathrm{C}=\mathrm{N}$ stretching vibrations are appeared in $1545 \mathrm{~cm}^{-1}$. The peaks around $3000 \mathrm{~cm}^{-1}$ are related to $\mathrm{C}-\mathrm{H}$ stretching vibrations.

The FTIR spectrum of adsorbed protective layer formed on the surface after immersion in $0.5 \mathrm{M}$ sulfuric acid containing optimum concentration of inhibitor is shown in Fig. 7. b. The $\mathrm{C}=\mathrm{N}$ stretching vibration at $1637 \mathrm{~cm}^{-1}$ shifting to higher wave numbers may be due to formation of the complex of $\mathrm{Fe}^{2+}-\mathrm{MOTAE}$ and adsorb on steel surface [35]. The presence of all the characteristic peaks in pure MOTAE in the spectrum of the adsorbed layer indicates the adsorption of inhibitor at the surface of steel [36]. The weak peak of $3745 \mathrm{~cm}^{-1}$ which do not exist in Fig. 9.a) is assigned to Fe-O bending [37] revealing the fact that adsorbed protective film is oxidized by $\mathrm{O}_{2}$ and $\mathrm{H}_{2} \mathrm{O}$ in air. The peak at $3447 \mathrm{~cm}^{-1}$ is attributed to O-H stretching, indicating that the protective film contains $\mathrm{H}_{2} \mathrm{O}$ [35].

\section{Scanning electron microscopy}

The effect of inhibitor on corrosion process was examined by the SEM micrograph of corroded steel surface in the absence and presence of inhibitor. The SEM images of the specimens in the $0.5 \mathrm{M} \mathrm{H}_{2} \mathrm{SO}_{4}$ solution in the absence and presence of corrosion inhibitor, are shown in Fig. 8.a and b, respectively. The morphology of carbon steel surface reveals that in the absence of MOTAE the surface is highly corroded in acid solution. However, in the presence of the inhibitor, the damage of the steel surface is significantly decreased. It can be deduced that, the inhibitor forms protective films by adsorption on the carbon steel surface and reduces the contact between the steel surface and the acid solution and, as a result, reduce the corrosion [38]. Therefore, SEM examination of the steel surface supports the results obtained from polarization and weight loss methods.

\section{Theoretical study}

The use of quantum chemical calculations is very important in studying the correlation between molecular structure and corrosion inhibition efficiency. Moreover, a theoretical study permits the pre-selection of compounds with the necessary structural characteristics to act as organic corrosion inhibitors [1]. In this study, quantum chemical calculations were conducted at three different quantum chemical levels by geometry optimization of the studied compound in order to support experimental data. Some quantum chemical parameters, which are thought important to directly influence on electronic interaction between iron surface and inhibitor, are calculated from the optimized structure of each level. The data are listed in Table 4. E $_{\text {Hомо }}$ : the energy of highest occupied molecular orbital, $E_{\text {Lumo: }}$ the energy of lowest unoccupied molecular orbital, $\Delta \mathrm{E}$ : the energy of $\mathrm{E}_{\mathrm{LUMO}}-\mathrm{E}_{\mathrm{HOMO}}, \mathrm{\eta}$ : absolute hardness, $\mathrm{S}$ : softness and $\mu$ : dipole moment. An increase in the values of $\mathrm{E}_{\text {ном }}$ can facilitate the adsorption and therefore the inhibition efficiency, by indicating the disposition of the molecule to donate the orbital electrons to an appropriate acceptor with empty molecular orbitals [39]. The energy of the lowest unoccupied molecular orbital, $E_{L U M O}$, indicates the ability of the molecule to accept electrons. Excellent corrosion inhibitors are usually those organic compounds which do not only offer electrons to unoccupied orbital of the

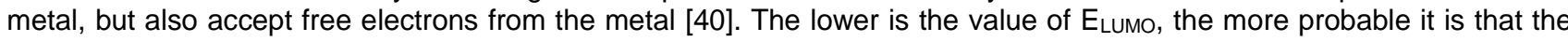
molecule accepts electrons [41]. Low values of the energy gap $\Delta \mathrm{E}=\mathrm{E}_{\mathrm{LUMO}}-\mathrm{E}_{\mathrm{HOMO}}$ will render good inhibition efficiencies, because the energy needed to remove an electron from the last occupied orbital will be low [40, 42]. 
According to theorem of Koopman, the $\mathrm{E}_{\text {Hомо }}$ of the inhibitor molecule is related to ionization potential (I), while $\mathrm{E}_{\text {LUMO }}$ is related to electron affinity $(A)[43]$ :

$\mathrm{I}=-\mathrm{E}_{\mathrm{HOMO}}$

$A=-E_{\text {LUMO }}$

Absolute hardness $(\eta)$ of the inhibitor molecule are given by Eq. (9)

$$
\eta=\frac{I-A}{2}
$$

The softness of inhibitor molecules are the inverse of absolute hardness [44]. Hardness and softness are important properties that reveal the molecular stability and reactivity. A hard molecule has a large energy gap and a soft molecule has a small energy gap. Soft molecules are more reactive than hard ones because they can easily offer electrons to an acceptor [45]. General rule suggested by the principle of HSAB (hard-soft-acid-base), is that hard acids prefer to coordinate to hard bases and soft acids prefer to coordinate to soft bases. On the other hand, metal atoms are known as soft acids, and thus soft bases inhibitors are the most effective for metals. So, the inhibition efficiency of inhibitors will increase by increasing softness [46].

Frontier orbital theory was useful in predicting the adsorption centers of the inhibitor molecule responsible for the interaction with surface metal atoms [47]. According to this theory, only frontier molecular orbitals are involved in interactions between reactants. Therefore, only the HOMO and LUMO of both reactants are considered when analyzing the chelation processes of chemical adsorption [1]. Fig. 9 shows the HOMO and LUMO populations of MOTAE obtained by three quantum chemical levels. It can be seen that the electron density distribution of the frontier orbitals obtained from the semi empirical (AM1) and DFT (B3LYP) levels are almost similar. It is found that the electron density of the frontier orbital is well proportioned. Such results indicate inhibitor could be both the acceptor of the electron and the donor of the electron. That is, there is electron transferring in the interaction between the inhibitor molecule and metal surface [48].

In general, electrophiles attack molecules at sites of negative charge, thus the sites of ionic reactivity can be estimated from the atomic charges in a molecule [49]. The use of Mulliken population analysis to probe the adsorption centers of inhibitors has been widely reported and it is mainly used to calculate the charge distribution over the whole skeleton of molecule [45]. Mulliken charges (with hydrogen's summed into heavy atoms) on each atom of the inhibitor, which are obtained by three quantum chemical levels, are gathered in Table 5. The assigned number of each atom inserted in Fig. 1. As seen, highest negative charges are located on the oxygen and nitrogen atoms (the most negative charge is located on the $\mathrm{N}_{21}$ ); reasonably these atoms can act as active centers in adsorption process.

\section{CONCLUSIONS}

[3-(4-methyl-pyridin-2-y1)-4-oxo-2-phenylimino-thiazolidin-5-ylidene]-acetic acid ethyl ester (MOTAE) acts as a mixed type inhibitor for carbon steel in $0.5 \mathrm{M}$ sulfuric acid solution. The IE\% values obtained from polarization measurements are consistent with those obtained from weight loss method. The adsorption of inhibitor on the steel surface obeys Langmuir adsorption isotherm. Thermodynamic parameters indicated that the adsorption process is exothermic and accompany by an increase in entropy. The formation of the adsorbed protective film on the carbon steel surface was also confirmed by FTIR studies. SEM images showed that, in the presence of the inhibitor, the damage of the steel surface is significantly reduced. The electron density distribution of the frontier orbitals obtained from the semi empirical (AM1) and DFT (B3LYP) levels are almost similar. Highest negative charges are located on the oxygen and nitrogen atoms (the most negative charge is located on the N21); reasonably these atoms can act as active centers in adsorption process. Overall, conclusion drawn from all of results i.e. thermodynamic values $(\Delta G)$, activation energy, FTIR and quantum chemical investigations collectively tends to affirm the both physical and chemical adsorption of inhibitor on the surface.

\section{REFERENCES}

[1] C.M. Goulart, A. Esteves-Souza, C.A. Martinez-Huitle, C.J.F. Rodrigues, M.A.M. Maciel, A. Echevarria, Corros. Sci. 67 (2013) 281-291.

[2] A.M. Al-Mayouf, A.A. Al-Suhybani, A.K. Al-Ameery, Desalination 116 (1998) 25-33.

[3] S.N. Raicheva, B.V. Aleksive, E.I. Sokolova, Corros. Sci. 34 (1993) 343-350.

[4] X.L. Cheng, H.Y. Ma, S.H. Chen, Z.M. Yao, Corros. Sci. 41 (1999) 321-333.

[5] B. Mernari, H. El-Attari, M. Traisnel, F. Bentiss, M. Lagrenee, Corros. Sci. 40 (1998) 391-399.

[6] B. G. Ateya, B. E. El-Anadouli, F. M. El-Nizamy, Corros. Sci. 24 (1984) 497-507.

[7] S.M.A. Hosseini, M.J. Bahrami, A. Dorehgiraee, Mater. Corros. 63 (2012) 627-635.

[8] M. Lebrini, M. Lagrenee, M. Traisnel, L. Gengembre, H. Vezin, F. Bentiss, Appl. Surf. sci. 253 (2007) 9267-9276.

[9] M.J. Bahrami, S.M.A. Hosseini, Inter. J. Ind. Chem. 3:30 (2012) 1-9.

[10] S.M.A. Hosseini, M. Salari, E. Jamalizadeh, S. Khezripoor, M. Seifi, Mater. Chem. Phys. 119 (2010) 100-105.

[11] S. M. A. Hosseini, A. Azimi, Corros. Sci. 51 (2009) 728-732.

[12] S. M. A. Hosseini, M. J. Bahrami, P. Pilvar, Mater. Corros. 61 (2010) 866-871. 
[13] H. H. Hassan, E. Abdelghani, M. A. Amin, Electrochem. Acta. 52 (2007) 6359-6366.

[14] D. Wang, S. Li, Y. Ying, M. Wang, H. Xiao, Z. Chen, Corros. Sci. 41 (1999) 1911-1919.

[15] V.V. Torres, V. A. Rayol, M. Magalhães, G.M. Viana, L.C.S. Aguiar, S.P. Machado, H. Orofino, E. D’Elia, , Corros. Sci. 79 (2014) 108-118.

[16] Gaussian 09, Revision A.02, M. J. Frisch, G. W. Trucks, H. B. Schlegel, G. E. Scuseria, M. A. Robb, J. R. Cheeseman, G. Scalmani, V. Barone, B. Mennucci, G. A. Petersson, H. Nakatsuji, M. Caricato, X. Li, H. P. Hratchian, A. F. Izmaylov, J. Bloino, G. Zheng, J. L. Sonnenberg, M. Hada, M. Ehara, K. Toyota, R. Fukuda, J. Hasegawa, M. Ishida, T. Nakajima, Y. Honda, O. Kitao, H. Nakai, T. Vreven, J. A. Montgomery, Jr., J. E. Peralta, F. Ogliaro, M. Bearpark, J. J. Heyd, E. Brothers, K. N. Kudin, V. N. Staroverov, R. Kobayashi, J. Normand, K. Raghavachari, A. Rendell, J. C. Burant, S. S. lyengar, J. Tomasi, M. Cossi, N. Rega, J. M. Millam, M. Klene, J. E. Knox, J. B. Cross, V. Bakken, C. Adamo, J. Jaramillo, R. Gomperts, R. E. Stratmann, O. Yazyev, A. J. Austin, R. Cammi, C. Pomelli, J. W. Ochterski, R. L. Martin, K. Morokuma, V. G. Zakrzewski, G. A. Voth, P. Salvador, J. J. Dannenberg, S. Dapprich, A. D. Daniels, O. Farkas, J. B. Foresman, J. V. Ortiz, J. Cioslowski, and D. J. Fox, Gaussian, Inc., Wallingford CT, 2009.

[17] A.K. Maayta, N. A. F. Al-Rawashded, Corros. Sci. 46 (2004) 1129-1140.

[18] E.S. Ferreira, C. Giancomelli, F.C. Giacomelli, A. Spinelli, Mater. Chem. Phys. 83 (2004) 129-134.

[19] I. Ahamad, M.A. Quraishi, Corros. Sci. 52 (2010) 651-656.

[20] E.E. Oguzie, Corros. Sci. 50 (2008) 2993-2998.

[21] M. Lebrini, F. Bentiss, H. Vezin, M. Lagrenee, Corros. Sci. 48 (2006) 1279-1291.

[22] S.M.A. Hosseini, A. Azimi, Mater. Corros. 59 (2008) 41-45.

[23] A. Popova, E. Sokolova, S. Raicheva, M. Christov, Corros. Sci. 45 (2003) 33-58.

[24] Y. Abboud. A. Abourriche, T. Saffaj, M. Berrada, M. Charrouf, A. Bennamara, N. Al Himidi, H. Hannache, Mater. Chem. Phys. 105 (2007) 1-5.

[25] M. bouklah, B. Hammouti, M. Lagrenee, F. Bentiss, Corros. Sci. 48 (2006) 2831-2842.

[26] S. A. Abd El-Maksoud, H. H. Hassan, Mater. Corros. 58 (2007) 369-375.

[27] E. M. Sherif, S. M. Park, Electrochim. Acta. 51 (2006) 6556-6562.

[28] J. W. Schultze, K. Wippermann, Electrochim. Acta. 32 (1987) 823-831.

[29] D. Seifzadeh, H. Basharnavaz, A. Bezaatpour, Mater. Chem. Phys. 138 (2013) 794-802.

[30] S.M.A. Hosseini, M. Salari, M.G. Motlagh , Corrosion 66 (2010) 1-12.

[31] A. Khamis, M.M. Saleh, M.I. Awad, Corros. Sci. 66 (2013) 343-349.

[32] S. Pournazari, M.H. Moayed, M. Rahimizadeh, Corros. Sci. 71 (2013) 20-31.

[33] A. Lalitha, S. Ramesh, S. Rajeswari, Electrochim. Acta 51 (2005) 47-55.

[34] Q. Qu, S.A. Jiang, W. Bai, L. Li, Electrochim. Acta 52 (2007) 6811-6820.

[35] X. Li, S. Deng, H. Fu, G. Muc, Corros. Sci. 51 (2009) 620-634.

[36] M. Yadav, D. Behera, U. Sharma, Arabian J. Chem. In press: DOI:10.1016/j.arabjc.2012.03.011

[37] Q. Qu, S.A. Jiang, L. Li, W. Bai, J. Zhou, Corros. Sci. 50 (2008) 35-40.

[38] Y. Tang, F. Zhang, S. Hu, Z. Cao, Z. Wu, W. Jing, Corros. Sci. 74 (2013) 271-282.

[39] G. Gece, S. Bilgic, O.Turksen, Mater. Corros. 61 (2010) 141-146.

[40] H. Ju, Z. P. Kai, Y. Li, Corros. Sci. 50 (2008) 865-871.

[41] M. Ozcan, I. Dehri, Prog. Org. Coat. 51 (2004) 181-187.

[42] I. B. Obot, N. O. Obi-Egbedi, S. A. Umoren, Corros. Sci. 51 (2009) 276-282.

[43] A.Y. Musa, A.A.H. Kadhum, A.B. Mohamad, A.A.B. Rahoma, H. Mesmari, J. Mol. Struct. 969 (2010) 233-237.

[44] K. Sayin, D. Karakas, Corros. Sci. 77 (2013) 37-45.

[45] L. Fragoza-Mar, O. Olivares-Xometl, M. A. Domínguez-Aguilar, E. A. Flores, P. Arellanes-Lozada, F. Jiménez-Cruz, Corros. Sci. 61 (2012) 171-184.

[46] M.K. Awad, M.S. Metwally, S.A. Soliman, A.A. El-Zomrawy, M.A. bedair, J. Indust. Engin. Chem. 20 (2014) 796-808.

[47] K. F. Khaled, M. M. Al-Qahtani, Mater. Chem. Phys. 113 (2009) 150-158. 
[48] X. Li, S. Deng, H. Fu, Prog. Org. Coat. 67 (2010) 420-426.

[49] J. Fang, J. Li, J. Mol. Struct. (Theochem) 593 (2002) 179-185.

\section{FIGURE /CAPTIONS :}

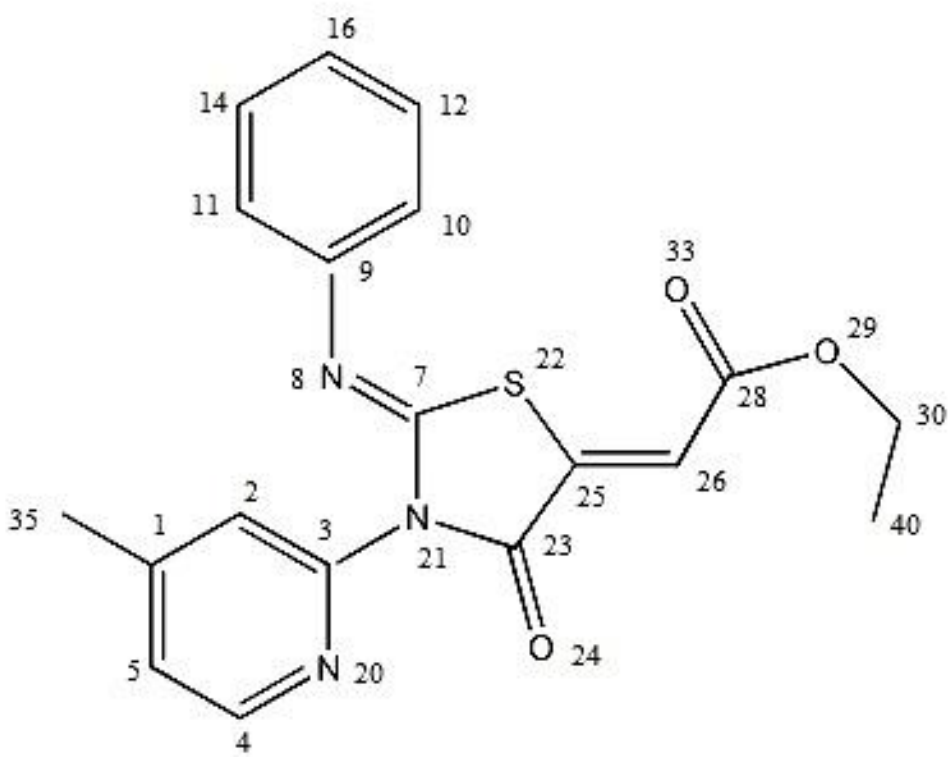

Fig. 1. The chemical structure of MOTAE

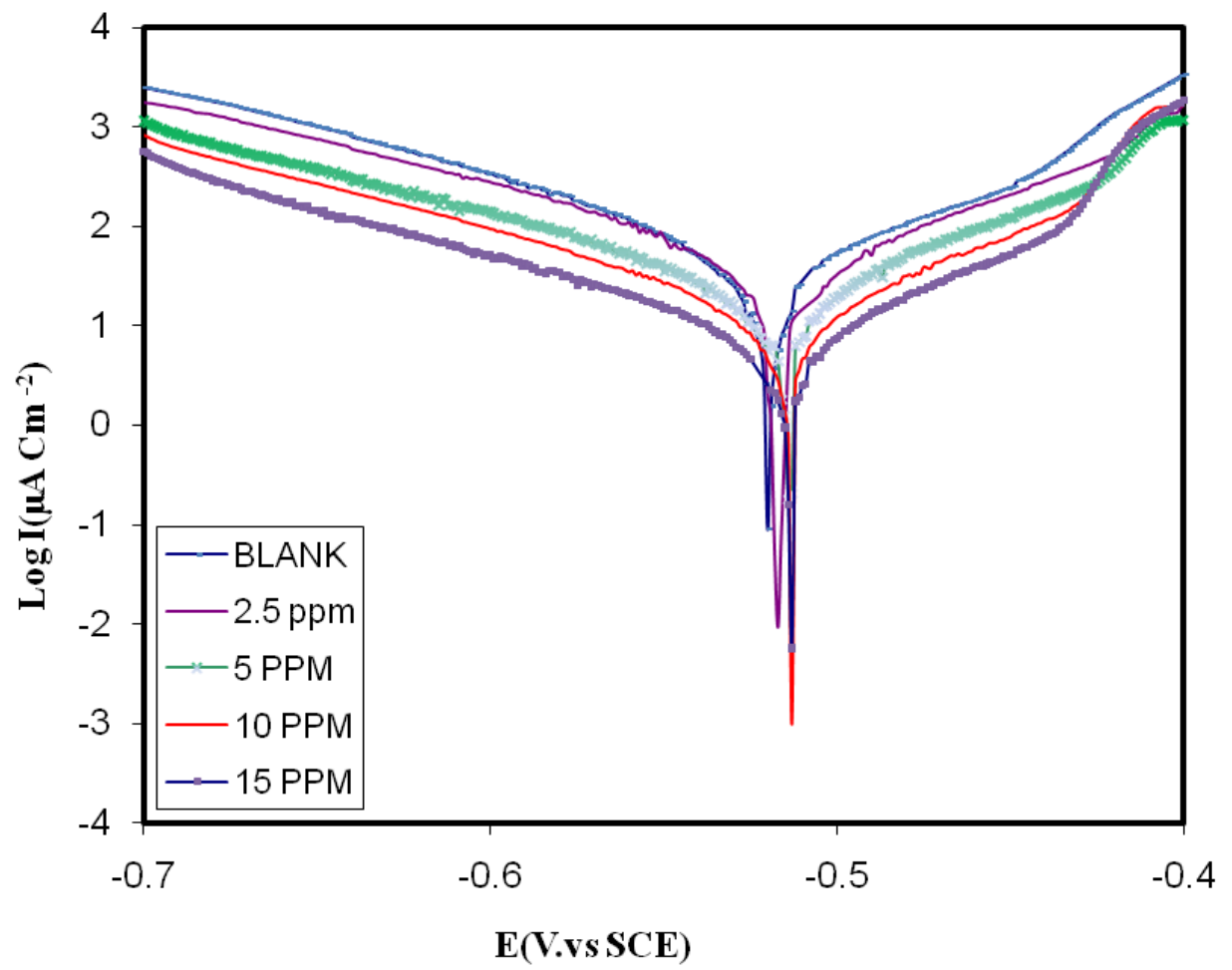

Fig. 2. The effect of increasing the concentration of inhibitor on polarization curves 

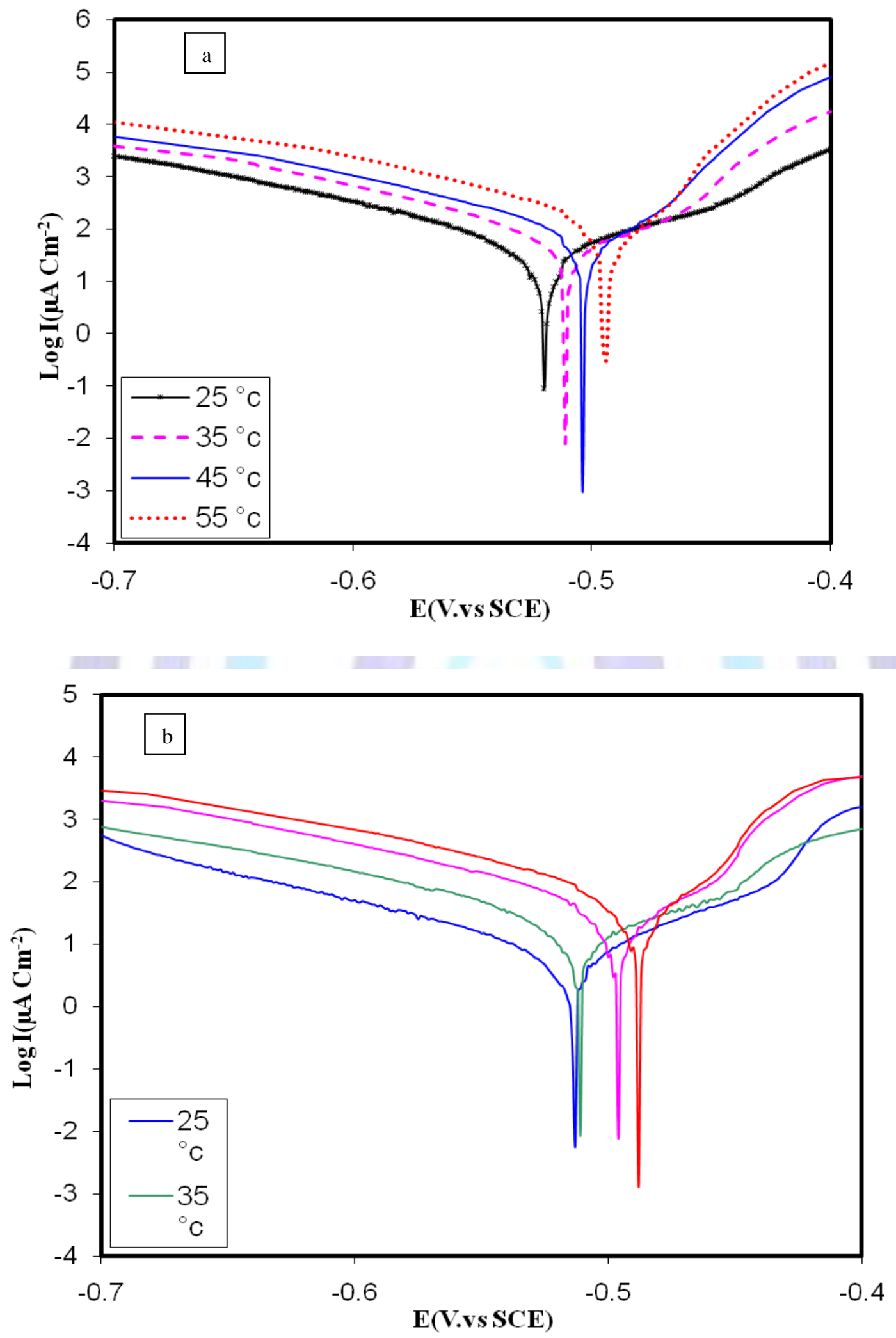

Fig. 3. The effect of temperature on polarization curves a) without inhibitor, b) in presence of $15 \mathrm{ppm}$ of MOTAE in $0.5 \mathrm{M}$ sulfuric acid solution 


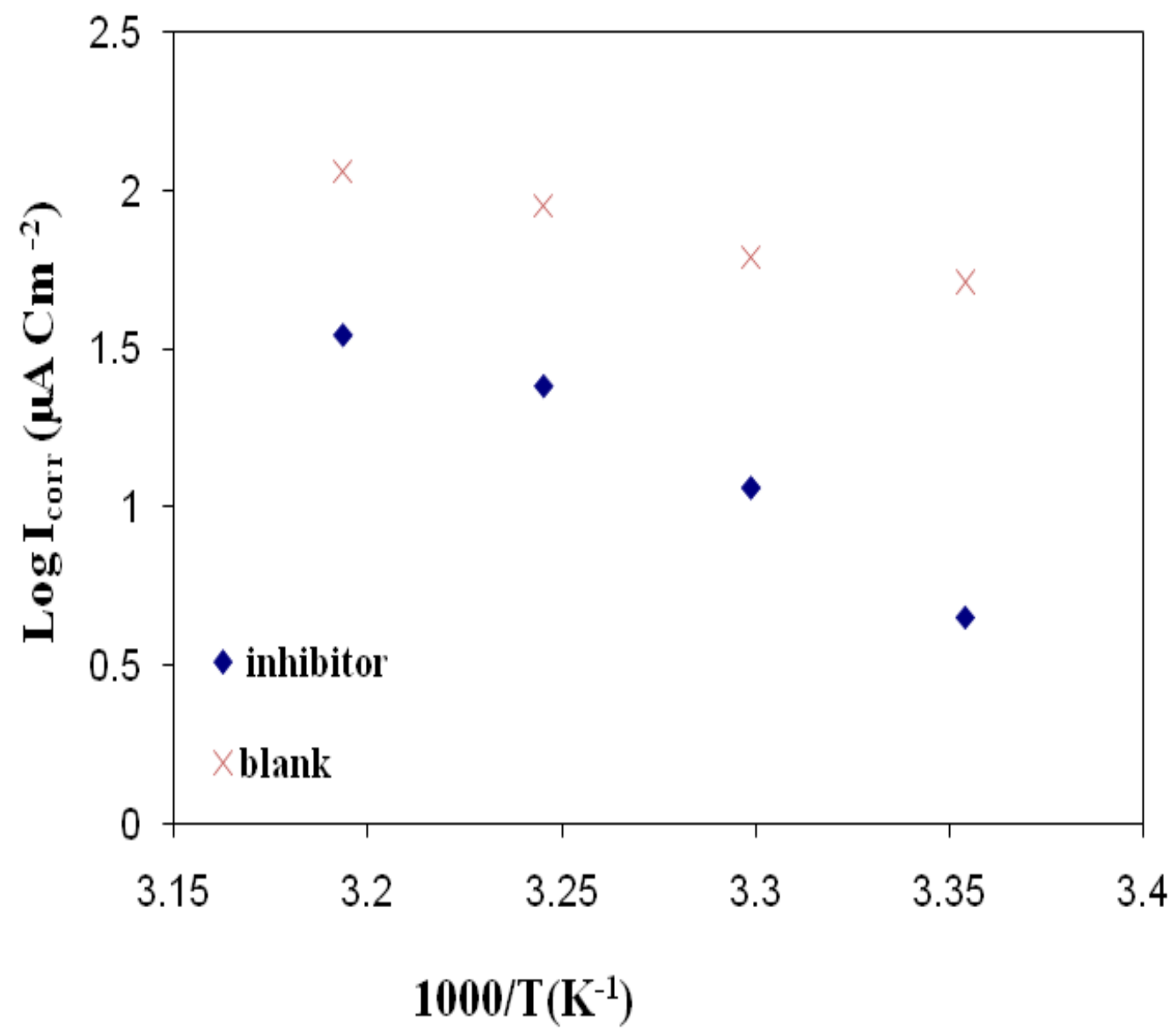

Fig. 4. Arrhenius slopes calculated from corrosion current density for carbon steel in: a) $0.5 \mathrm{M}$ sulfuric acid and b) $0.5 \mathrm{M}$ sulfuric acid + $15 \mathrm{ppm}$ MOTAE

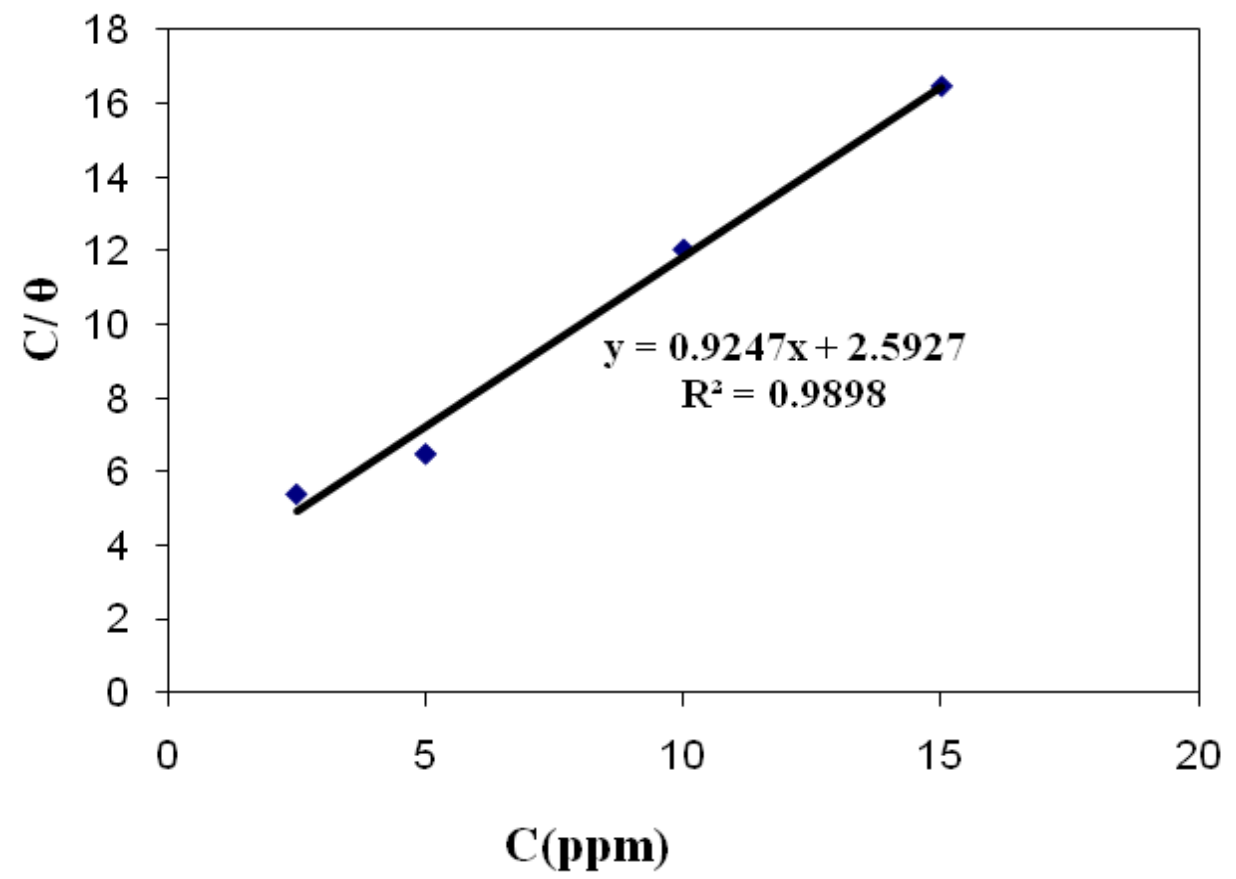

Fig. 5. Langmuir adsorption isotherm of MOTAE on carbon steel surface in $0.5 \mathrm{M}$ sulfuric acid solution 


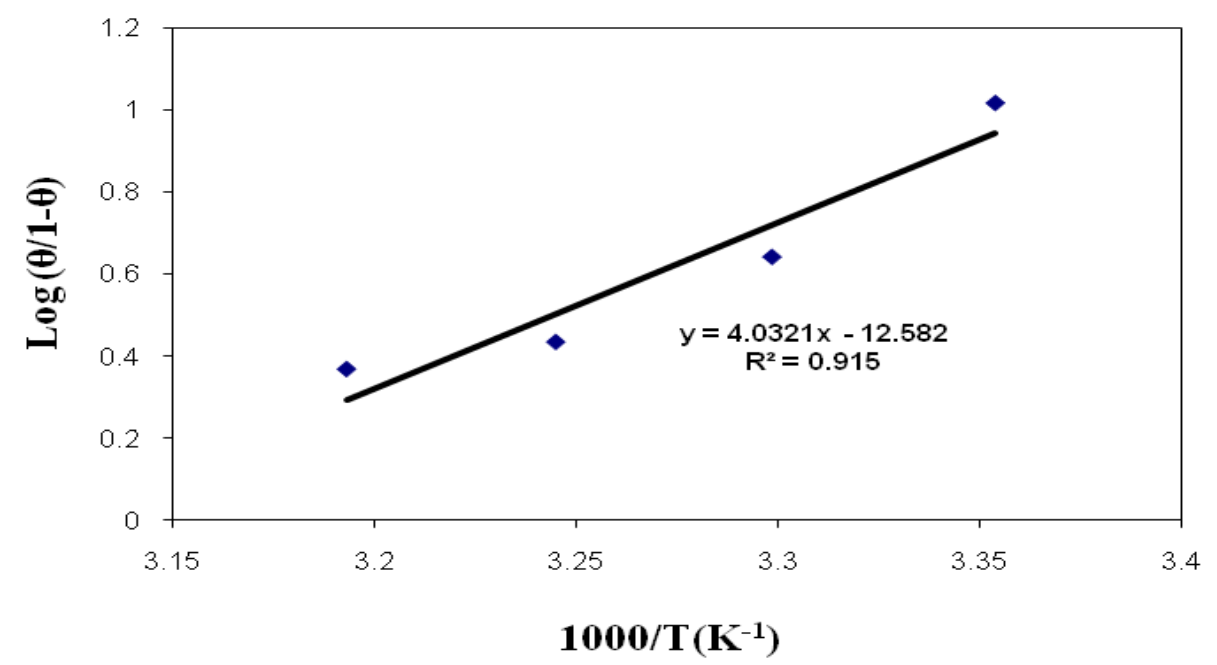

Fig. 6. Plot of $\log (\theta / 1-\theta)$ versus $1 / \mathrm{T}$ for carbon steel in $0.5 \mathrm{M}$ sulfuric acid solution containing 15 ppm MOTAE
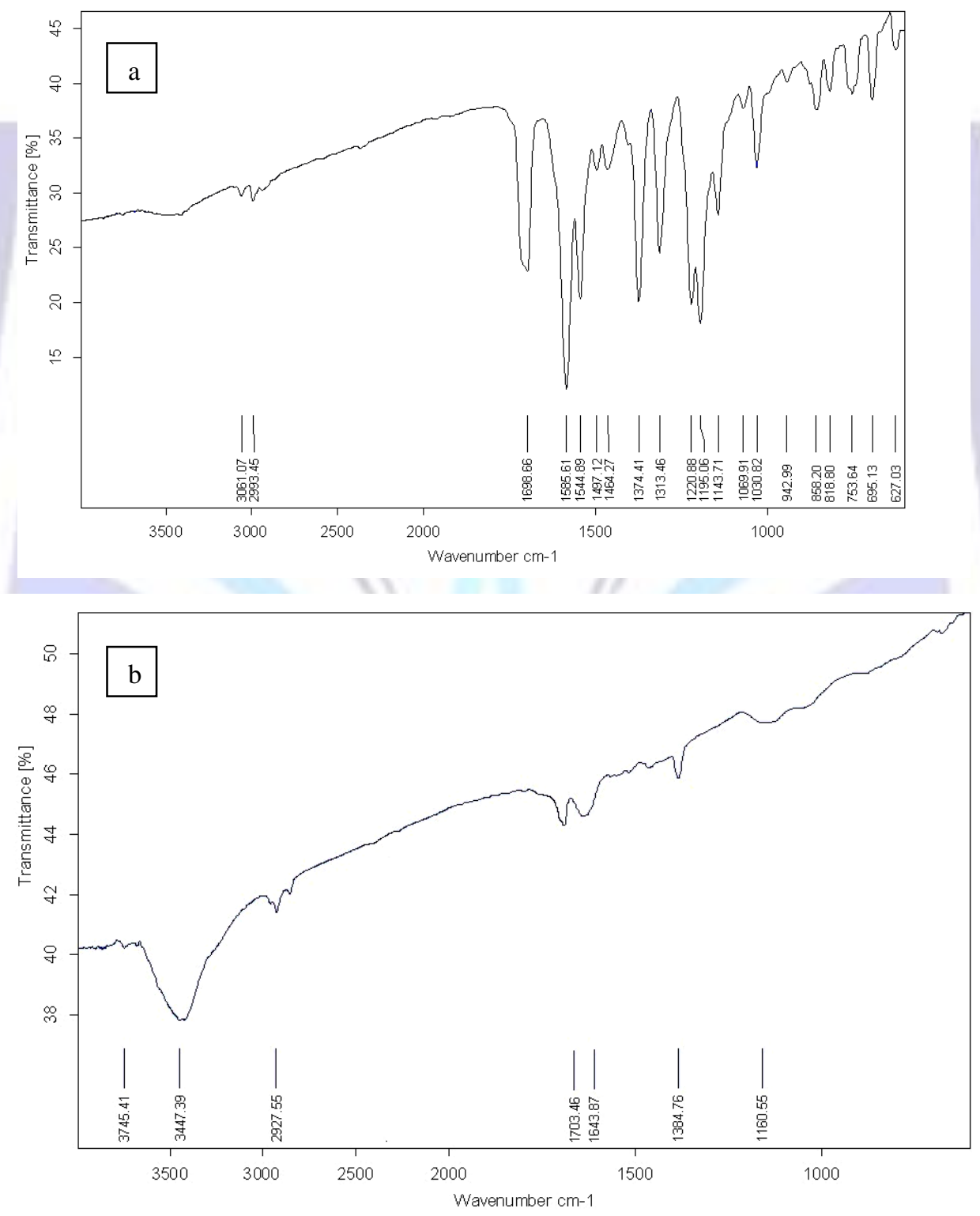

Fig. 7. FTIR spectra of a) pure DBT and b) adsorbed layer formed on the steel surface, after immersion in $0.5 \mathrm{M}$ sulfuric acid solution + 15 ppm MOTAE for 24 hours 

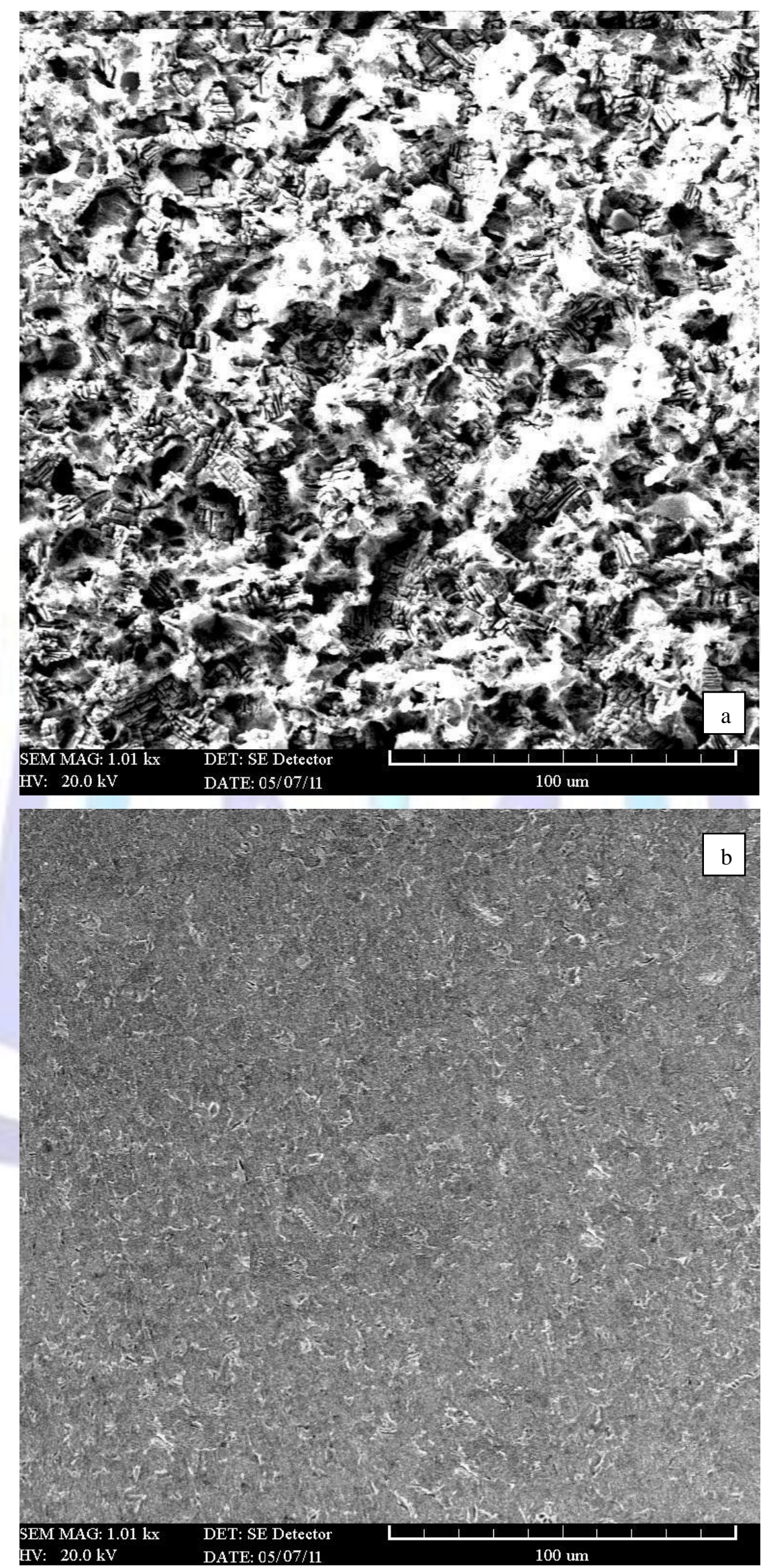

Fig. 8. SEM images of carbon steel in a) $0.5 \mathrm{M}$ sulfuric acid b) $0.5 \mathrm{M}$ sulfuric acid + $15 \mathrm{ppm}$ MOTAE 

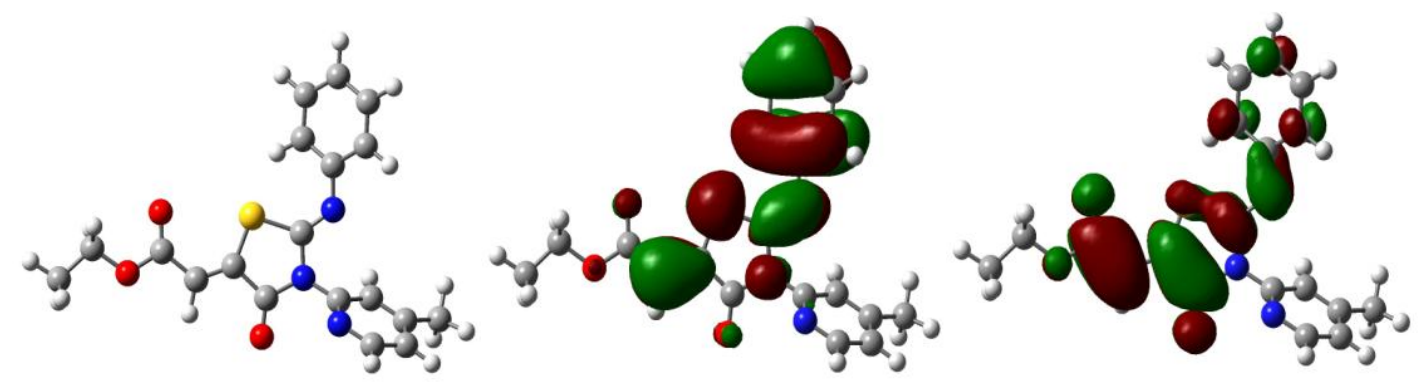

(a)
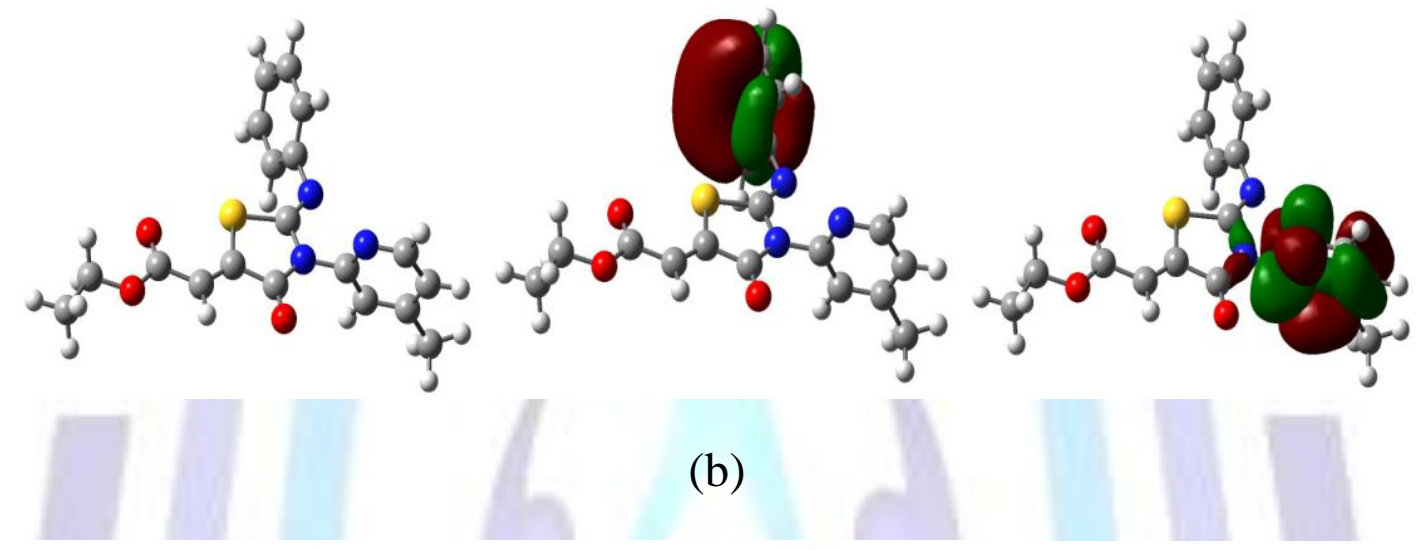

(b)
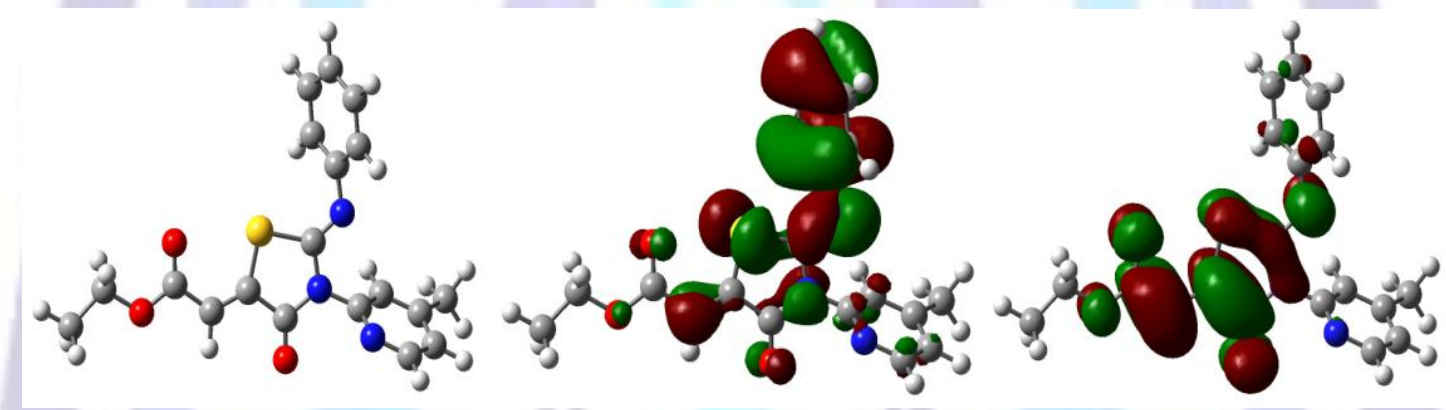

(c)

Fig. 9. The optimized structure (left) and HOMO (center) and LUMO (right) distribution for inhibitor in different calculation methods, a) AM1, b) HF and c) B3LYP

\section{Table Captions:}

Table 1. Corrosion parameters derived from polarization and weight loss measurements in $0.5 \mathrm{M} \mathrm{H}_{2} \mathrm{SO}_{4} \mathrm{solution}$ containing different concentrations of inhibitor.

Table 2. Corrosion parameters calculated from polarization measurements for carbon steel in absence and presence of optimum concentration of inhibitor at different temperatures.

Table 3. Thermodynamic parameters for adsorption of inhibitor in $0.5 \mathrm{M} \mathrm{H}_{2} \mathrm{SO}_{4}$ on the metal surface.

Table 4. Quantum chemical parameter values of inhibitor obtained by three investigated methods.

Table 5. Mulliken charges of atoms (with hydrogen's summed into heavy atoms) of compound obtained by three investigated methods. 
Table 1. Corrosion parameters derived from polarization and weight loss measurements in $0.5 \mathrm{M} \mathrm{H}_{2} \mathrm{SO}_{4}$ solution containing different concentrations of inhibitor.

\begin{tabular}{cccccccc}
\hline $\begin{array}{c}\text { Concentration } \\
(\mathrm{ppm})\end{array}$ & $\begin{array}{c}\mathrm{i}_{\text {corr }} \\
\left(\mu \mathrm{A} / \mathrm{Cm}^{2}\right)\end{array}$ & $\begin{array}{c}\mathrm{E}_{\text {corr }} \\
(\mathrm{mV})\end{array}$ & $\begin{array}{c}\beta_{\mathrm{c}} \\
\left(\mathrm{mV} \mathrm{dec}^{-1}\right)\end{array}$ & $\begin{array}{c}\beta_{\mathrm{a}} \\
\left(\mathrm{mV} \mathrm{dec}^{-1}\right)\end{array}$ & $\theta$ & $\mathrm{IE} \%$ & $\mathrm{~W}_{\mathrm{L}}(\mathrm{IE} \%)$ \\
\hline blank & 51.3 & -525 & 85 & 85 & --- & --- & --- \\
2.5 & 27.5 & -520 & 80 & 60 & 0.463 & 46.3 & 48 \\
5 & 11.8 & -520 & 50 & 55 & 0.770 & 77.0 & 75 \\
10 & 8.6 & -515 & 50 & 65 & 0.832 & 83.2 & 84 \\
15 & 4.5 & -515 & 50 & 55 & 0.912 & 91.2 & 93 \\
\hline
\end{tabular}

Table 2. Corrosion parameters calculated from polarization measurements for carbon steel in absence and presence of optimum concentration of inhibitor at different temperatures.

\begin{tabular}{lcccc}
\hline \multirow{4}{*}{ blank } & $\begin{array}{c}\text { Temperature } \\
\left({ }^{\circ} \mathrm{C}\right)\end{array}$ & $\begin{array}{c}\mathrm{i}_{\text {corr }} \\
\left(\mu \mathrm{A} / \mathrm{cm}^{2}\right)\end{array}$ & $\begin{array}{c}\mathrm{E}_{\text {corr }} \\
(\mathrm{mV})\end{array}$ & IE\% \\
\cline { 2 - 5 } & 25 & 51.3 & -515 & --- \\
& 35 & 61.7 & -510 & --- \\
& 45 & 89.1 & -505 & --- \\
\hline \multirow{3}{*}{ inhibitor } & 55 & 114.8 & -495 & --- \\
\hline & 25 & 4.5 & -515 & 91.2 \\
& 35 & 11.5 & -510 & 81.4 \\
& 45 & 24 & -495 & 73.1 \\
& 55 & 34.7 & -488 & 69.8 \\
\hline
\end{tabular}

Table 3. Thermodynamic parameters for adsorption of inhibitor in $0.5 \mathrm{M} \mathrm{H}_{2} \mathrm{SO}_{4}$ on the metal surface.
$\mathrm{E}_{\mathrm{a}}\left(\mathrm{kJ} \mathrm{mol}^{-1}\right)$
$\Delta \mathrm{H}\left(\mathrm{kJ} \mathrm{mol}^{-1}\right)$
$\Delta \mathrm{G}\left(\mathrm{kJ} \mathrm{mol}^{-1}\right)$
$\Delta \mathrm{S}\left(\mathrm{J} \mathrm{mol}^{-1} \mathrm{~K}^{-1}\right)$

blank

18.7

Inhibitor

46.4

$-33.5$

$-39.3$

0.019 


\begin{tabular}{ccccccccc}
$\begin{array}{c}\text { Quantum } \\
\text { parameter }\end{array}$ & $\begin{array}{c}\mathrm{IE} \%(\mathrm{~W} \& \mathrm{P} \\
)\end{array}$ & $\begin{array}{c}\mathrm{E}_{\mathrm{HOMO}} \\
(\mathrm{eV})\end{array}$ & $\begin{array}{c}\mathrm{E}_{\mathrm{LUMO}} \\
(\mathrm{eV})\end{array}$ & $\Delta E(\mathrm{eV})$ & $\mu(\mathrm{D})$ & hardness & softness & Point group \\
\hline DFT & 91.2 & -5.968 & -2.2994 & 3.6686 & 2.1185 & 1.8343 & 0.5452 & $\mathrm{C} 1$ \\
\hline HF & 91.2 & -8.401 & 1.626 & 10.027 & 1.9353 & 5.0135 & 0.1995 & $\mathrm{C} 1$ \\
\hline AM1 & 91.2 & -8.8418 & -1.2259 & 7.6159 & 1.9577 & 3.8079 & 0.2626 & $\mathrm{C} 1$ \\
\hline
\end{tabular}

Table 4. Quantum chemical parameter values of inhibitor obtained by three investigated methods.

Table 5. Mulliken charges of atoms (with hydrogen's summed into heavy atoms) of compound obtained by three investigated methods.

\begin{tabular}{|c|c|c|c|c|}
\hline \multirow[t]{2}{*}{ atoms } & \multicolumn{4}{|c|}{ Mulliken charges } \\
\hline & DFT & $\mathrm{HF}$ & AM1 & average \\
\hline C1 & 0.139659 & 0.042392 & $\begin{array}{c}- \\
0.027627\end{array}$ & 0.051475 \\
\hline $\mathrm{C} 2$ & 0.015625 & 0.005058 & 0.022103 & 0.014262 \\
\hline C3 & 0.431374 & 0.567995 & 0.108258 & 0.369209 \\
\hline C4 & 0.202784 & 0.291680 & 0.112013 & 0.202159 \\
\hline C5 & -0.032698 & -0.050630 & $0 .-2891$ & -0.038740 \\
\hline C7 & 0.316119 & 0.432716 & 0.026591 & 0.240748 \\
\hline N8 & -0.525955 & -0.592514 & 0.159679 & -0.426049 \\
\hline C9 & 0.203254 & 0.161742 & 0.000128 & 0.121708 \\
\hline C10 & 0.006266 & 0.010899 & 0.010165 & 0.002333 \\
\hline C11 & 0.007695 & 0.026508 & 0.052360 & 0.029632 \\
\hline C12 & -0.005726 & 0.010746 & 0.020789 & 0.008603 \\
\hline $\mathrm{C} 14$ & -0.005260 & 0.009080 & 0.007752 & 0.003857 \\
\hline $\mathrm{C} 16$ & 0.002152 & -0.009853 & 0.010623 & 0.000974 \\
\hline N20 & -0.444740 & -0.539028 & $0.14^{-} 2243$ & -0.375248 \\
\hline N21 & -0.586366 & -0.844905 & 0.233143 & -0.554805 \\
\hline S22 & 0.301581 & 0.383072 & 0.394838 & 0.359830 \\
\hline $\mathrm{C} 23$ & 0.643005 & 0.871384 & 0.344513 & 0.619634 \\
\hline
\end{tabular}




\section{ISSN 2321-807X}

\begin{tabular}{|c|c|c|c|c|}
\hline $\mathrm{O} 24$ & -0.469597 & -0.560508 & $\begin{array}{c}- \\
0.257987\end{array}$ & -0.429364 \\
\hline C25 & -0.171104 & -0.286645 & $\begin{array}{c}- \\
0.291584\end{array}$ & -0.249778 \\
\hline $\mathrm{C} 26$ & -0.006480 & -0.000892 & 0.082498 & 0.025042 \\
\hline $\mathrm{C} 28$ & 0.626207 & 0.820766 & 0.326293 & 0.591089 \\
\hline O29 & -0.481754 & -0.639709 & $\begin{array}{c}- \\
0.269182\end{array}$ & -0.463548 \\
\hline $\mathrm{C} 30$ & 0.299912 & 0.367598 & 0.175485 & 0.280998 \\
\hline O33 & -0.495230 & -0.583371 & $\begin{array}{c}- \\
0.343707\end{array}$ & -0.474103 \\
\hline C35 & 0.006773 & 0.072367 & 0.088428 & 0.055856 \\
\hline C40 & 0.022505 & 0.034054 & 0.048720 & 0.035093 \\
\hline
\end{tabular}

